\title{
Analysis on the Professional Ability Training of Normal University Students in New Industrial Age
}

\author{
Lanyan Qin, Biqiong Zhou* \\ Xiangnan University, Chenzhou, Hunan, 423000, China \\ *Corresponding author.
}

\begin{abstract}
The professional training of normal university students has always been highly concerned by the society especially in the new industrial age. The professional-oriented training of normal university students is closely related to the future teacher occupation and teaching quality. It also affects the construction of high-quality teachers in the future. Faced with the problems encountered in the professional training of normal university students in recent years, this article put forward feasible training methods based on the actual situation to improve to cultivate qualified professional teachers.
\end{abstract}

Keywords: Professional ability, training, normal university students, industrial

\section{Introduction}

Like most other professions, the teacher has a "learning" nature, with each practitioner supplementing their professional knowledge and skills from time to time throughout their career. With economic development and technological progress, society pays more and more attention to the quality of teachers. How to adapt to the development of the times, strengthen the professional ability of normal university students and meet the high-quality requirements of education reform for future teachers has become an important subject of teaching reform in normal colleges.

\section{II.Definition of Professional Training of Normal University Students}

Teacher professionalization refers to the process of professional growth of teachers in the whole career, through specialized training and lifelong learning, they gradually acquire the knowledge and skills of education profession and constantly improve their own teaching quality in the practice of education profession. It contains two levels of significance: the process of sustainable professional development of individual teachers from a novice to a mature teacher with professional knowledge, professional skills and professional attitude through pre-service training, and it also refers to the process of the overall progress of teacher occupation from non-professional and quasi-professional occupation to professional occupation [1]. In this paper, teacher professional training refers to the pre-service professional training process of normal university students. Teacher's professional development is composed of professional knowledge, professional quality and professional skills, including education and teaching ability and teaching skills, among which teaching skills involve questioning skills, communication skills, blackboard writing skills, flexible handling of teaching emergencies, etc. Teaching ability refers to teaching design ability, teaching expression ability and course organization and management ability.

\section{III.The Importance of Professional Training of Normal University Students}

\subsection{Improving the quality of teachers}

To revitalize teacher education, it is necessary to improve the quality of teachers and cultivate a high-quality team of teachers. Improving the quality of teacher training has become the core and most urgent task of China's teacher education reform and development. In 2015, China implemented the national unified examination for teacher qualification and raised the entry threshold for teachers. The inspection of teachers' basic qualities changed from the 
previous emphasis on theoretical knowledge to the combination of knowledge and teaching skills, and the inspection content paid more attention to the comprehensive quality. The quality of teachers is closely related to the quality of education. To enhance the professionalism of teachers in normal university students is the fundamental measure to promote the reform of quality-oriented education. The professional training of teachers in normal university students is the key to improve the quality of teachers in the future

\subsection{Promoting curriculum reform}

Teachers are the executors of teaching curriculum and the main force of curriculum reform. Teachers' professional quality, professional spirit, teaching concept and educational attitude are the supporting force of curriculum reform, and also the internal driving force of curriculum reform [2]. Only by enhancing the professional degree of teachers in normal universities can the curriculum reform of basic education be guaranteed by high-quality teachers.

\subsection{Promoting the development of normal university students themselves}

The teaching profession can not only enable the educators to grow by "preaching and resolving doubts", but also enable the educators themselves to make progress in this process. Only by constantly improving themselves consciously can the educators better promote the progress of the students. The process of teacher specialization itself is the process of continuous self-improvement and self-perfection. As the backbone of the future education, normal university students should constantly improve their professional level of teachers, and the university should put into practice the teaching concept and purpose of "student-oriented", so as to provide a fundamental guarantee for the development and improvement of normal university students' professional ability.

\section{IV.The present situation of Professional Training of Normal University Students}

\subsection{The practice lesson is less and the curriculum setting is unreasonable}

The normal curriculum system of universities is mainly divided into disciplinary and professional courses, public basic courses and educational courses.andthe proportion of practical courses in educational courses is very low. Most of the professional courses are pure theoretical. Although at this stage project of cultivating college students highlight the conditional knowledge, such as pedagogy and psychology and discipline knowledge, but there is still a lack of practical knowledge teaching content. More practical courses, such as pedagogy, microteaching or educational statistics and measurement, account for less, and even where there are courses, there is more emphasis on theoretical explanations. There is a positive correlation between teachers' career development and educational practice courses, such as students' psychological counseling, class management, dealing with unexpected teaching events and other teaching contents, which play a very important role in shortening the career adaptation cycle of new teachers. In the actual investigation process, it is found that normal university students have a strong willingness to learn practical teaching skills courses.

4.2 The cultivation method of teacher ethics is single, and the students lack enthusiasm and initiative

In the new era, the requirement of teacher specialization is no longer limited to professional skills, but has expanded to the level of teacher ethics. The key to cultivate normal university students with firm teacher belief, highteacher quality and deep professional emotion is the practice of teacher ethics education. Moral education practice course is very important for normal university students to understand the connotation of teachers' ethics, improve their cognition of the professional value of teachers and set up a correct view of education. However, the current cultivation method of teachers' ethics is too simple, and the practical operation has not obtained satisfactory cultivation effect.

Under the influence of employment situation, family environment, interests and hobbies, some normal university students do not have a correct cognition of the teaching profession. A considerable number of normal university 
students choose normal major due to the requirement of parents or the influence of family conditions, rather than the independent choice based on their own will. Some normal students find themselves more interested in other majors once they enter the university, or simply apply to change majors. In order to improve the success rate of employment, some normal university students actively prepare for exams for civil servants, public institutions and other occupations after entering school. Some normal university students have low learning enthusiasm in their major. They just participate in the learning process in order to successfully graduate. At the same time, they are vague about career goals, do not pay attention to the study of professional knowledge, and lack of enthusiasm and initiative for in-depth study.

\subsection{The construction of professional training facilities for normal university students is not sufficient}

Since the 20th century, with the development of higher education reform, many normal universities have been transformed into comprehensive universities, which has weakened the characteristics of normal education. At the same time, because the expanding enrollment, some comprehensive colleges and universities have set up professional teachers' department.Because the number of students enrollment is not much, and there is no active in combination with the actual situation of the students' professional training, and the facilities construction is not enough, the development of teachers' specialty in these schools has been affected .

At the present stage, based on the development status of vocational skills education for normal university students, compared with comprehensive colleges, normal colleges have more abundant accumulation in teaching practice, so the vocational training of normal university students has more advantages. In addition, the development of vocational ability training of normal university students in the same kind of colleges and universities is unbalanced due to the influence of historical accumulation, the attention of leaders and the allocation of educational resources.

\subsection{The current evaluation mechanism is lack of science and standardization}

On the one hand, training should be carried out according to certain plans; on the other hand, it is necessary to mobilize the enthusiasm of normal university students in an all-round way and provide a strong guarantee for the training of various professional skills of teachers by combining the evaluation mechanism with clear and planned division of projects. However, most normal universities only form a standardized assessment mechanism for some simple skills such as "three characters and one picture", which rarely involves the assessment of other professional skills of normal university students, let alone a reasonable assessment standard. The lack of motivation is a common problem in the professional training of normal university teachers, and one of the reasons for this problem is that the evaluation mechanism is not scientific and normative, and there is no rigid management method for skill training.

\section{Strategies for improving Professional Training of Normal University Students}

\subsection{Optimize curriculum setting}

The curriculum should meet the needs of teachers' professional development in the new era and the original curriculum should be adjusted to meet the needs of the society. Through the reform of education curriculum, the educational quality of normal university students can be effectively improved and the professional development of teachers can be promoted. The realization of this goal must start from the current normal university students and carry out systematic learning of teaching scientific theoretical knowledge [3]. Optimizing the demonstration course can start from the following four aspects. First of all, modern educational technology courses such as network education, micro-teaching, multimedia courseware making and development can be added appropriately, so that normal university students can master the latest and most practical educational and teaching information means and methods, and enhance the ability of information teaching. Secondly, with the change and development of The Times, teachers in the future will face a lot of psychological problems to solve and deal with, the existing normal courses must fully take into account the students' psychological knowledge and ability to learn, increase the length of educational psychology courses; Thirdly, at present, normal university students are most short of practical knowledge courses of education subjects, and the contents of teachers' oral English, lecture-speaking, class 
teacher's work and three-pen characters should be properly added in the curriculum setting. Fourthly, the reform of normal curriculum must be combined with the reform of primary and secondary schools, and the reform of basic education should be considered. The new curriculum content of middle school curriculum reform, new curriculum standard analysis and entrance examination for secondary school or college research can be taken as appropriate. And so on.

\subsection{Strengthen the practice of teachers' ethics}

Practice is the most direct and effective way for people to explore, solve and think about problems. The most efficient way to deeply embed the connotation of teacher's ethics education into the minds of normal university students is to participate in practice and improve students' cognition of teacher's ethics. The practice of teachers' ethics, as an important link in the cultivation of teachers' ethics, should first improve the management system of education practice [4], do a good job of publicity on the basis of formulating the management regulations of education practice, and adjust students' attitude towards education and learning. Secondly, based on the reality, students should be encouraged to carry out investigation and research on teachers' ethics in education, and understand the significance of teachers' ethics education through understanding the realistic demands of teachers' ethics. Thirdly, we should expand the classroom of teachers' ethics, enrich the content of teachers' ethics, organize students to participate in various activities, stimulate students' teachers' feelings by holding various moral lecture halls, and cultivate teachers' professional dedication spirit and sense of responsibility.

\subsection{Strengthen the training of professional practice cultivation}

At present, the most deficiency of normal university students is the study of educational practical knowledge. First of all, a complete practical teaching system should be constructed to ensure the systematic training of teaching skills for students. Competence decomposition should be carried out with teachers' professional competence as the core, and some courses with strong practicality should be added, such as subject teaching design, multimedia technology application, and comprehensive practice activities [5]. The research proves that the generation of teachers' professional competence needs a lot of teaching scenes, and the full and deep experience of certain teaching scenes is conducive to the development of teachers' professional competence of normal university students. For example can make use of modern education technology and high quality video teaching resources to provide students with more high quality teaching situation [6], microteaching system can be used to guide students to carry out the simulation teaching, view to discuss, such as training, through careful organization design and creation of the environment, in practice, accumulation, analysis and summary, To generate teachers' professional competence of normal university students through situational perception. We can also invite famous teachers from local primary and secondary schools to hold a series of lectures on campus to bring the most authentic cases of teacher education to normal university students. Finally, it is necessary to make reasonable use of educational apprenticeship and internship to further strengthen the teaching ability of normal university students. Educational practice is an important part of normal education, the embodiment of applying theoretical knowledge to practice, and the indispensable link of training qualified teachers. The current teaching practice for normal university students generally adopts the mode of intensive practice, which lasts 6-8 weeks and is arranged to be completed in the first semester of the senior year. The main content of the internship is the teaching of professional courses. It is difficult for normal university students to adapt to a profession in just a few weeks. In many cases, as soon as normal university students are familiar with the teaching environment and enter the role, their internship will end. To optimize the teaching practice of normal university students, we can extend the practice time appropriately, increase the number of teaching apprenticeship, and enrich the practice content. The teachingpractice can take the way of combination of probation and practice. The probation scattered in each semester, so that students have the opportunity to go deep into primary and secondary schools, close contact with the work of teachers, to understand the reality of teaching. The time to participate in the practice for Students should be extend, so students can integrated application in teaching practice with the basic theory of education, professional knowledge and education skills, and familiar with the work of teachers gradually. Normal university students should not only practice the teaching of professional courses in the process of the internship, but also participate in extracurricular 
tutoring, class management and other work, so as to enrich the internship content and comprehensively improve the professional ability.

5.4Adopt a variety of assessment and evaluation methods

Evaluation is an important part in teacher professional skills training. In the process of teacher professional training for normal university students, normal universities need to build a complete, scientific and standardized evaluation mechanism by comprehensively combining the assessment standards, systems, contents and methods. First of all, an evaluation system should be constructed to restrain students and teachers' professional skills training with the help of rules and regulations, so as to ensure the level of training work. Secondly, to determine the comprehensiveness of the evaluation content, the evaluation content should involve multiple plates, including teachers' basic skills, educational skills, teaching skills, teaching and research skills, etc.; Thirdly, the evaluation standards should be refined, the weight of each evaluation item should be determined based on the characteristics and content of teachers' professional skills, and the scientific nature of evaluation indicators should be improved to avoid subjective evaluation behavior. Finally, the evaluation method should be adjusted, and the evaluation method should have dynamic and diversified characteristics, and the evaluation content should be diversified. At the same time, it is necessary to ensure the comprehensiveness of the evaluation link, combining the result evaluation with the formative evaluation, the teacher evaluation with the student evaluation, the society evaluation with the school evaluation.

In a word, the professional training of normal university students is a process of continuous development. The particularity of the teaching profession determines that the professional development is the pursuit of the whole career. More attention to the professional training of normal university students needs to be paid. Normal universities should build a systematic skill training system in line with the professional development of normal university students, effectively assist the professional development of normal university students, and improve their professional skills.

\section{Acknowledgement}

This paper is funded by 2018 Hunan Provincial Department of Education Scientific Research Project: Research and Practice on Training Teachers in Local Universities under the Background of National Teacher Qualification Examination. (18C1012);2019 Hunan Province General University Teaching Reform Research Project: The Comparative Research and Practice of Pre-service Teacher Training Mode under the Background of Teacher Qualification Certification [HNJG-2019-291, Xiang Jiao Tong [2019] No. 815];2020 Chenzhou "Thirteenth Five-year Plan", School-school Cooperation Special Project (CJK20XXHZ17).[2019social achievements evaluation committeeproject no. XSP19YBZ134], [2019 ideological work quality improvement project no.19c17], [2020 Scientific research projects no.20C1713][2019 Chenzhou social science project no.Czssk12019087 ].[2020 College Students' innovation project no.3692].

\section{References}

[1] W. Chen. “Teacher Professionalization in Western Universities," Peking University Press, 2008

[2] S. Zhang, S.Z. Jiang. "Research on the Professional Skilled Training of Normal College Teachers in the New Era,” Modern Vocational Education, vol. 0, no. 34, pp. 184-185, 2018.

[3] Y. Fang. Research on Teacher Ethics Education of Normal University Students in the New Era.2019.

[4] Q.Q. Zhang, W.Y. Zhu. “An Investigation on Teachers' Professional Quality of Normal University Students -- A Case Study of Mathematics Major in W University,” Journal of JinzhongUniversity, vol. 35, no. 5, pp. 73-77, 2018.

[5] F.J. Tang. Practical Literacy of Teachers of Normal Specialty in Universities and Its Generation Path.2019. 
CONVERTER MAGAZINE

Volume 2021, No. 4

[6] H.W. Li, X.H. Meng. "An Analysis on the Professional Ability Cultivation of Local Normal College Mathematics Teachers," College Mathematics, vol. 36, no. 5, pp. 38-42, 2020.

ISSN: 0010-8189

(C) CONVERTER 2020

www.converter-magazine.info 